\title{
FUZZY LOGIC BASED FIELD ORIENTED CONTROL OF PERMANENT MAGNET SYNCHRONOUS MOTOR
}

\author{
${ }^{1}$ BINITA NANDA, ${ }^{2}$ A.N THAKUR \\ ${ }^{1}$ M.Tech, Department of Electrical and Electronics Engineering, NIT Jamshedpur \\ ${ }^{2}$ Professor, Department of Electrical and Electronics Engineering, NIT Jamshedpur \\ E-mail: ${ }^{1}$ bini.n.pgrace@gmail.com, ${ }^{2}$ anthakur.ee@ nitjsr.ac.in
}

\begin{abstract}
The present research is indicating that the Permanent magnet motor drive could become serious competitor to the induction motor drive for servo application. Further, with the evolution of permanent magnet materials and control technology, the Permanent Magnet Synchronous Motor (PMSM) has become a pronounced choice for low and mid power applications such as computer peripheral equipments, robotics, adjustable speed drives and electric vehicles due to its special features like high power density, high torque/inertia ratio, high operating efficiency, variable speed operation, reliability, and low cost etc. However, the main disadvantage of PMSM is the non-uniform variance in the developed torque. Vector controlled PMSM drive provides better dynamic response and lesser torque ripples. This paper proposes a Fuzzy logic control scheme for a PMSM drive driven by Field Oriented Control (FOC). The proposed scheme is developed in MATLAB/SIMULINK environment. Simulation results are generated for testing the performance validity of the control law.
\end{abstract}

Index Terms- Permanent Magnet Synchronous Motor, Fuzzy Logic Control, Vector Control, Field Oriented Control.

\section{INTRODUCTION}

The Permanent Magnet Synchronous motor (PMSM) is a rotating electrical machine where the stator produces a sinusoidal flux density distribution in the air gap and the rotor has permanent magnets. From the last three decades AC machine drives are becoming more and more popular, especially Induction Motor Drives (IMD) and Permanent Magnet Synchronous Motor (PMSM), but with some special features, the PMSM drives are ready to meet sophisticated requirements such as fast dynamic response, high power factor, and wide operating speed range like high performance applications, as a result, a gradual gain in the use of PMSM drives will surely be witnessed in the future market in low and mid power applications [1]. Now in a permanent magnet synchronous machine, the dc field winding of the rotor is replaced by a permanent magnet to produce the air-gap magnetic field. Having the magnets on the rotor, some electrical losses due to field winding of the machine get reduced and the absence of the field losses improves the thermal characteristics of the PM machines hence its efficiency. Also lack of mechanical components such as brushes and slip rings makes the motor lighter, high power to weight ratio which assure a higher efficiency and reliability. With the advantages described above, permanent magnet synchronous generator is an attractive solution for wind turbine applications also. Like always, PM machines also have some disadvantages: at high temperature, the magnet gets demagnetized, difficulties to manufacture and high cost of PM material. The performance of these motors in drive systems depend up on the motor control and method of control in power converter. The method of motor control is very important in the drive system. This is because the operation of the PMSM under effect of scalar control is suffered from complicated coupling nonlinear dynamic performance. This problem can be solved by field oriented control (FOC). PMSM with FOC emulates the separately excited DC motor. The control of an ac motor in field co-ordinates (also known as field oriented control or transvektor control) as proposed by Blaschke[2] for an induction machine and later by Bayer et al. [3] for a synchronous machine, leads to a decoupling between the flux and the torque resulting in a good dynamic torque and speed response [4]. In this method of control, the stator current can be decupled into flux and torque current components. They can be controlled separately. Vector control (or Field Oriented Control) principle makes the analysis and control of Permanent Magnet Synchronous Motor (PMSM) drives system simpler and provides better dynamic response. It is also widely applied in many areas where servo- like high performance plays a secondary role to reliability and energy savings. This paper presents the field oriented vector control scheme for permanent magnet synchronous motor (PMSM) drives, which regulates the speed of the PMSM. The performance of the motor suffers from uncertainties, parameters variation, and harmonics in both motor and inverter. They lead to problems in torque and oscillations in the speed come out as the secondary problem from the torque problem. To solve this problem, the torque must be studied.

The motor torque is a sum of: 1) Mutual torque, due to the interaction of the rotor field and stator 
currents; 2) Reluctance torque, due to rotor saliency; 3) Cogging torque, due to the existence of stator slots. These torques contain harmonics which lead to torque ripples. The mutual torque and reluctance torque have harmonics if the stator flux or rotor magnets are non- sinusoidal. The reluctance torque is exists only if the inductance is a function in the rotor position. The cogging torque arises due to geometry and slots in the PMSM. The machine design and control technique are used to reduce the torque ripple. The first method is complicated and high cost so the other method is preferable. Proportional integrator controller (PI), it is the most common controllers used in a wide range in the industrial applications. The popularity of PI control can be attributed to its simplicity. Due to its fixed proportional gain and integral time constant, the performance of the PI controllers are affected by parameter variations, load disturbances and speed variation. These problems can be overcome by the Fuzzy logic controller, which do not require any mathematical model and is based on the linguistic rules obtained from the experience of the system operator. SPWM and SVPWM can be used for effective switching of the inverter and the proposed system can be simulated using MATLAB/ Simulink environment.

\section{MATHEMATICAL MODEL OF PMSM}

The mathematical model of a PMSM is similar to that of wound rotor synchronous motor. The rotor winding of synchronous motor is replaced with high resistivity permanent magnet material, hence induced current in the rotor are negligible. The rotor types of PMSM are shown in Fig. 1. The permanent magnets on the rotor are shaped in such a way as to produce sinusoidal back EMF in stator windings. The following equations represents the PMSM model where $v_{d}$ and $v_{q}$ are the $\mathrm{d}$ and $\mathrm{q}$ axis terminal voltages; $i_{d}$ and $i_{q}$ are the $\mathrm{d}$ and $\mathrm{q}$ axis currents; $r$ is the winding resistance; $L_{d}$ and $L_{q}$ are the $\mathrm{d}$ and $\mathrm{q}$ axis self inductances; $\theta_{e}$ is the angle between the rotor and $\mathrm{d}$ axis. $\omega_{e}$ is the angular speed of the rotor; $J$ is the rotor moment of inertia; $B$ is the damping coefficient; $T_{m}$ is the developed torque and $T_{L}$ is the load torque.

$$
\begin{aligned}
& v_{d}=r i_{d}+L_{d} \frac{d i_{d}}{d t}-\omega_{e} L_{q} i_{q} \\
& v_{q}=r i_{q}+L_{q} \frac{d i_{q}}{d t}-\omega_{e} L_{d} i_{d}+\omega_{e} \psi_{P M} . \\
& J \frac{d \omega_{m}}{d t}=T_{m}-T_{L}-B \omega_{m}
\end{aligned}
$$

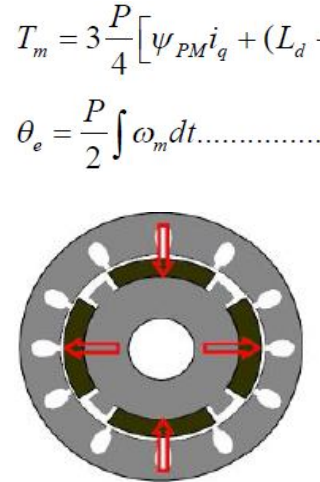

(a)
Fig. 1: The types of rotor in PMSM: (a) PM surface inset, (b)PM surface interior (buried)

\section{FOC PMSM DRIVE SYSTEM}

Scalar control is somewhat simple to implement, but the inherent coupling effect (both torque and flux are functions of voltage or current and frequency) gives sluggish response and the system is easily prone to instability because of a higher order system effect. The invention of the vector control in the beginning of 1970s and the demonstration that an Induction Motor can be controlled like a separately excited dc motor brought a renaissance in the high-performance control of AC drives. Because of dc machine like performance, vector control is also known as decoupling, orthogonal or transvektor control.

In case of PMSM, the main flux is produced by permanent magnets $\psi_{P M}$ on the rotor. The current through the stator coils produces a flux called the armature reaction flux $\psi_{a}$, because the stator of the synchronous machine represents the armature. Then the total stator flux is given as a vector sum of both of these fluxes. $\beta$ is the torque angle, the angle between the vector of stator current $I_{s}$ and the

direct axis which is aligned with the vector of the permanent magnet flux on the rotor. The armature reaction flux $\psi_{a}=L_{a} I_{s}$, where $L_{a}$ is defined as the stator inductance can be resolved to d-q frame as follows:

$$
\begin{aligned}
& \psi_{a d}=L_{d} I_{d}=L_{d} I_{s} \cos \beta . \\
& \psi_{a q}=L_{q} I_{q}=L_{q} I_{s} \sin \beta \ldots
\end{aligned}
$$

Then the total flux in the d-q frame is given as:

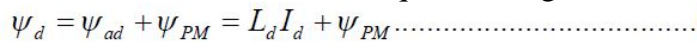

$$
\begin{aligned}
& \psi_{q}=\psi_{a q}=L_{q} I_{q} \cdots \\
& \psi_{s}^{2}=\left(L_{q} I_{s} \sin \beta\right)^{2}+\left(L_{d} I_{s} \cos \beta+\psi_{P M}\right)^{2} \text {. }
\end{aligned}
$$

As it can be seen in Fig.2, the magnitude of the total stator flux depends on the location and magnitude of the stator current phasor. For example, the motor excited by the nominal flux during no-load steady 
state operation produces a small no load stator current. Then the armature reaction fluxes in the $\mathrm{d}-\mathrm{q}$ frame are negligible. In this case the magnitudes of the total stator flux and the flux produced by the permanent magnets are considered to be same: $\psi_{P M} \cong \psi_{s}$

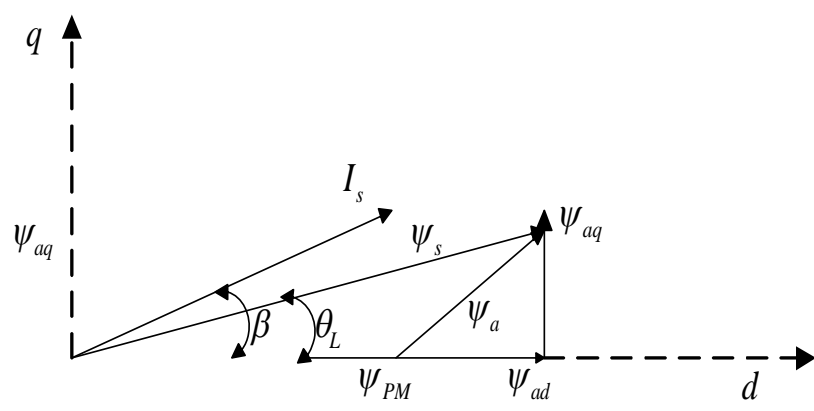

Fig.2: Phasor Diagram Illustrating Relation Between Stator Fluxes And Stator Current.

In case the vector of the stator current is located in a manner that its d-component is in the same direction and in the same sense as flux of PM, the total flux in $\mathrm{d}$-axis is given as a sum of the permanent magnet flux $\psi_{P M}$ and of the contribution of the armature reaction flux in the d-axis $\left(\psi_{a d}=L_{d} I_{d}\right)$. Flux $\psi_{s}$ represents the total flux in the machine and the induced voltage $E_{s}$ generated by this flux is higher than the induced voltage $E_{P M}$ generated by the magnet, Fig. 3(a). On the contrary, if the vector of the stator current in d-axis is in opposite sense to the flux of Permanent Magnet, the total flux in d-axis is given as difference between the permanent magnet flux $\psi_{P M}$ and the contribution of the armature flux in d-axis. The induced voltage $E_{s}$ generated by the main flux is lower than the induced voltage $E_{P M}$ generated by permanent magnet Fig. 3(b).

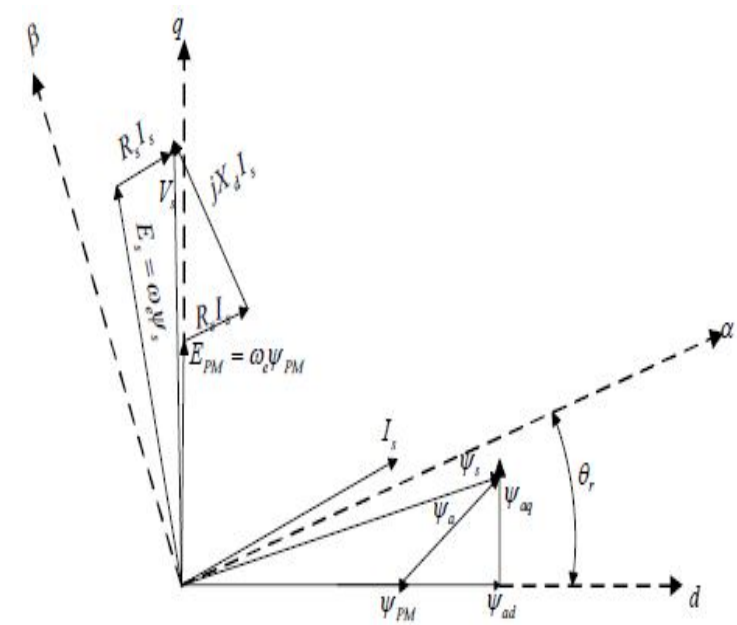

Fig. 3(A): Overexcited Mode

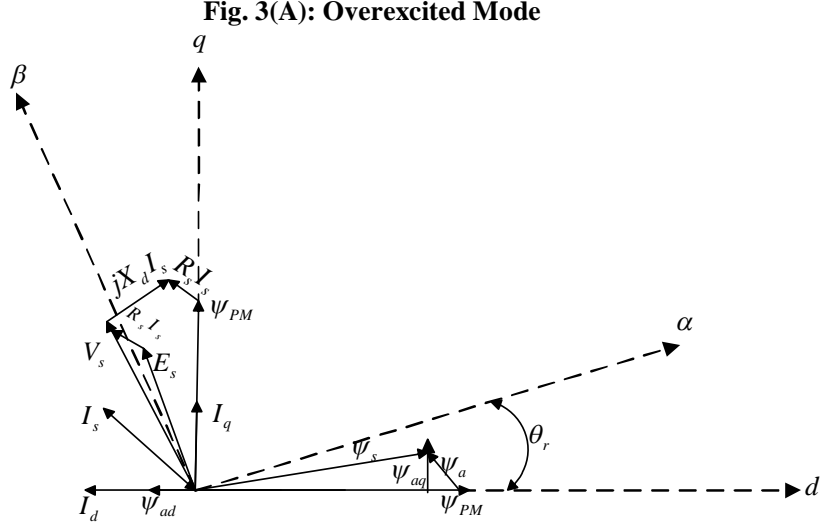

Fig. 3(B): Underexcited Mode

The vector control of PMSM allows separate closed loop control of both the flux and torque, hence achieving a similar control structure to that of a separately excited DC machine.

Electromagnetic torque expressed in d-q components of current is given as:

$$
T_{e}=\frac{3 p}{2}\left[\psi_{P M} i_{q}+i_{d} i_{q}\left(L_{d}-L_{q}\right)\right]
$$

For simplification, if a smooth air gap is assumed and if on the rotor only the permanent magnets represent the source excitation, the electromagnetic torque is expressed as

$T_{e}=\frac{3 p}{2} \psi_{P M} i_{q}$

General expression of torque can be written as:

$T_{e}=\frac{3 p}{2} \psi_{P M}\left|i_{s}\right| \sin \beta$.

$\psi_{P M}$ is assumed to be constant. For a given value of stator current, the maximum torque can be obtained with an angle of $\beta=90^{\circ}$ as explained in Fig.4. This mode of operation gives the maximum torque per ampere of stator current and therefore a higher efficiency.

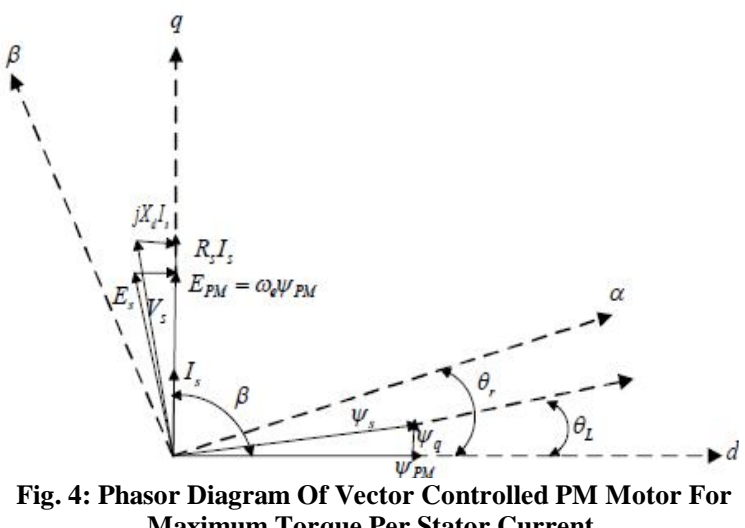
Maximum Torque Per Stator Current.

The torque request is generated by the speed controller in dependence on the speed error. By keeping $I_{d}$ current frozen at zero, the phasor of 
stator current will be placed just in quadrature axis. (Fig. 4) and the maximal driving torque will be achieved. This can be done by setting the demanded current to zero. The d-component of stator current is kept at zero all the time and the magnitudes of the total stator flux and the flux of the Permanent Magnet are equal. Using such a control strategy avoids the motor to become under or over-excited. The block diagram of proposed FOC with PI or Fuzzy logic based controller (FLC) for the PMSM drive is shown in Fig.5.

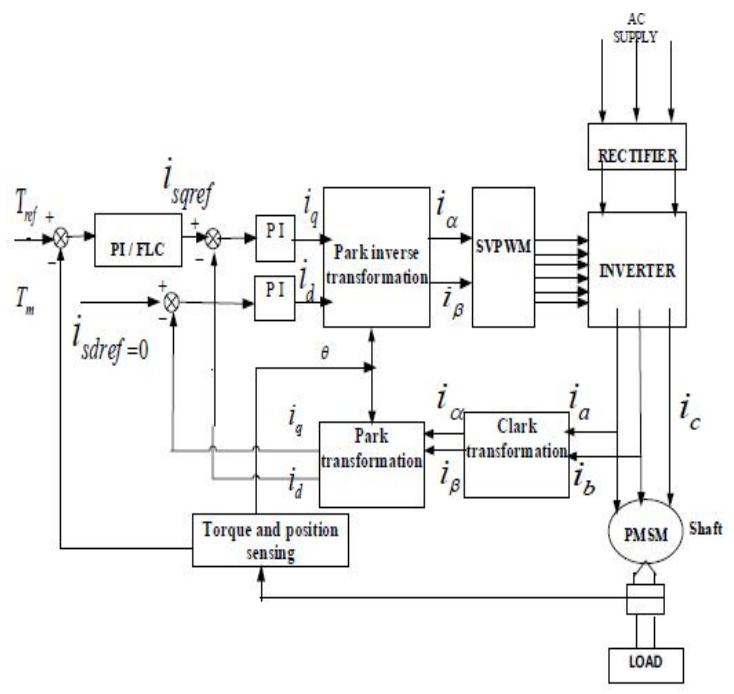

Fig.5: Block Diagram Of PMSM Drive With FOC Using Fuzzy Logic Controller.

Single phase AC supply is given to the inverter through the rectifier. The inverter feeds the PMSM which drives the load. The 3 phase currents $i_{a}, i_{b}, i_{c}$ are measured. $i_{c}$ is calculated using the relationship:

$i_{a}+i_{b}+i_{c}=0$

The Clarke transformation is applied to determine the stator current projection in the two co-ordinates $(\alpha, \beta)$ stationary frames. The transformation from the three phase system into the two dimension orthogonal system is given by the relations:

$$
\begin{aligned}
& i_{\alpha}=i_{a} \\
& i_{\beta}=\frac{i_{a}+2 i_{b}}{\sqrt{3}} .
\end{aligned}
$$

The Park transformation is then applied in order to obtain this projection in the $\mathrm{d}$, q- rotating frame. The relationship between the two reference frames can be obtained from the following equations.

$$
\begin{aligned}
& i_{d}=i_{\alpha} \cos \theta+i_{\beta} \sin \theta \\
& i_{q}=-i_{\alpha} \sin \theta+i_{\beta} \cos \theta .
\end{aligned}
$$

The torque is sensed from the motor and it is compared with the reference torque. The error signal is given either to the PI or Fuzzy Logic Controller. The PI or FLC calculates reference torque, which is proportional to the quadrature axis stator current component $i_{\text {sqref }}$. The $\mathrm{d}, \mathrm{q}$ projections of the stator phase currents are then compared to their reference values $i_{\text {sdref }}$ and $i_{\text {sqref }}$ and are corrected by means of PI controllers. The outputs of the current controllers are passed through the inverse Park transform and a new stator voltage vector is impressed to the motor using space vector pulse width modulation (SPWM).

\section{SPACE VECTOR PULSE WIDTH MODULATION (SPWM)}

Space vector modulation is a one of the advanced pulse width modulation (PWM) technique used for inverter switching. Usually there are eight possible switching states in an inverter. In these six are active vectors. This PWM technique approximates the reference voltage $V_{\text {ref }}$ by a combination of the eight switching patterns $\left(\mathrm{V}_{0}\right.$ to $\mathrm{V}_{7}$ ) are described in the Fig. 6 with the switching patterns and output voltages of a three-phase power inverter in Table 1. To implement the space vector PWM, the voltage equations in the abc reference frame can be transformed into the stationary $\alpha, \beta$ reference frame that consists of the horizontal $(\alpha)$ and vertical $(\beta)$ axes, as a result, six non-zero vectors and two zero vectors are possible.

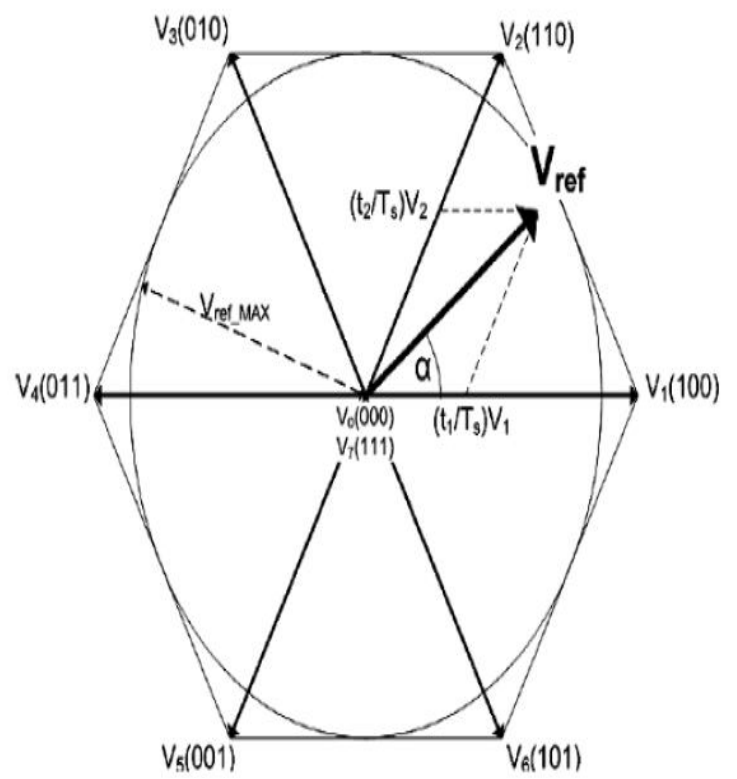

Fig. 6: Switching vectors and sectors

The required space vector $V_{r e f}$ can be generated using two neighboring active vectors $V_{1}$ and $V_{2}$ for 
a time period of $t_{1}$ and $t_{2}$ respectively along with null vectors for a time period of $\left(T_{s}-\left(t_{1}\right.\right.$ $\left.+t_{2}\right)$ ), where $T_{s}$ is the switching period.

Table 1: Switching Patterns of SVM

\begin{tabular}{|c|l|l|l|l|l|l|l|l|l|}
\hline Vector & $\mathrm{A}^{+}$ & $\mathrm{B}+$ & $\mathrm{C}+$ & $\mathrm{A}-$ & $\mathrm{B}-$ & $\mathrm{C}-$ & $\mathrm{AB}_{\mathrm{AB}}$ & $\mathrm{BC}_{\mathrm{BC}}$ \\
\hline $\mathrm{V}_{0}=\{000\}$ & 0 & 0 & 0 & 1 & 1 & 1 & 0 & 0 & 0 \\
\hline $\mathrm{V}_{1}=\{100\}$ & 1 & 0 & 0 & 0 & 1 & 1 & $-\mathrm{V}_{\mathrm{dc}}$ & 0 & $\mathrm{~V}_{\mathrm{dc}}$ \\
\hline $\mathrm{V}_{2}=\{110\}$ & 1 & 1 & 0 & 0 & 0 & 1 & 0 & $-\mathrm{V}_{\mathrm{dc}}$ & $\mathrm{V}_{\mathrm{dc}}$ \\
\hline $\mathrm{V}_{3}=\{010\}$ & 0 & 1 & 0 & 1 & 0 & 1 & $-\mathrm{V}_{\mathrm{dc}}$ & $-\mathrm{V}_{\mathrm{dc}}$ & 0 \\
\hline $\mathrm{V}_{4}=\{011\}$ & 0 & 1 & 1 & 1 & 0 & 0 & $-\mathrm{V}_{\mathrm{dc}}$ & 0 & $+\mathrm{V}_{\mathrm{dc}}$ \\
\hline $\mathrm{V}_{5}=\{001\}$ & 0 & 0 & 1 & 1 & 1 & 0 & 0 & $\mathrm{~V}_{\mathrm{dc}}$ & $\mathrm{V}_{\mathrm{dc}}$ \\
\hline $\mathrm{V}_{6}=\{101\}$ & 0 & 0 & 1 & 0 & 1 & 0 & $-\mathrm{V}_{\mathrm{dc}}$ & $-\mathrm{V}_{\mathrm{dc}}$ & 0 \\
\hline $\mathrm{V}_{7}=\{111\}$ & 0 & 1 & 1 & 0 & 0 & 0 & 0 & 0 & 0 \\
\hline
\end{tabular}

\section{TORQUE CONTROLLER}

The design of the torque controller is important from the point of view of imparting desired transient and steady-state characteristics to the torque-controlled PMSM drive system.

\section{A. PI CONTROLLER}

A proportional plus integral controller is sufficient for many industrial applications and hence, it is considered in this section. The torque error between the electromagnetic torque and its reference, given by $\left(T_{r e f}-T_{m}\right)$, is processed through a proportional plus integral (PI) type controller. PI controllers are used widely for motion control systems. They consist of a proportional gain that produces an output proportional to the input error and an integration gain to minimize the steady state error zero for a step change in the input. Two parameters are used to design this controller. These parameters are proportional gain $\left(k_{p}\right)$ and integral gain $\left(k_{i}\right)$. This controller can be represented as:

$$
G(s)=k_{p}+\frac{k_{i}}{s}
$$

\section{B. FUZZY LOGIC CONTROLLER (FLC)}

The concept of "Fuzzy Logic" was first introduced by Lotfi A. Zadeh in 1965 with a novel proposal of Fuzzy Set Theory. Fuzzy logics had been studied since the 1920s as infinite-valued logics notably by Łukasiewicz and Tarski. Fuzzy logic theory is an artificial intelligence method which has been has been employed to many fields like control theory to artificial intelligence.

Among the various intelligent controllers, fuzzy logic controller (FLC) is the simplest, robust and better than others in terms of quick response time, also insensitivity to parameter and load variations etc [6-8]. Thus, here a FLC is implemented as another speed controller for proposed vector control of IPMSM drive and also to study the performance comparison of the proposed IPMSM drive with conventional PI controller based drive in MATLAB/Simulink environment.

The inputs to the FLC are Torque error (e) and change in torque error $(\Delta e)$. The FLC initially converts the crisp error and change in torque error into fuzzy variables and then are mapped into linguistic labels. The inputs and output contain membership functions with five linguistic variables; namely HN- High Negative, LN- Less Negative, ZEZero, HP-High Positive, LP- Less Positive and the rules for generating the controller is shown in the Table 2. The Fig. 7(a) shows the speed error, Fig. 7(b) shows the change in speed error and Fig. 7(c) shows the torque limit of the FLC.

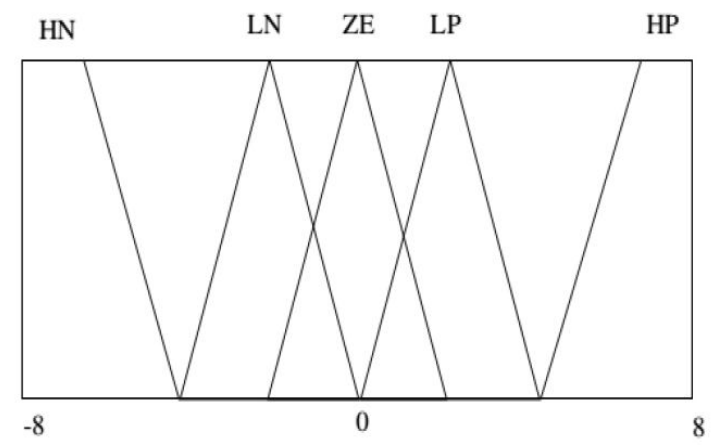

Fig. 7(A) Speed Error

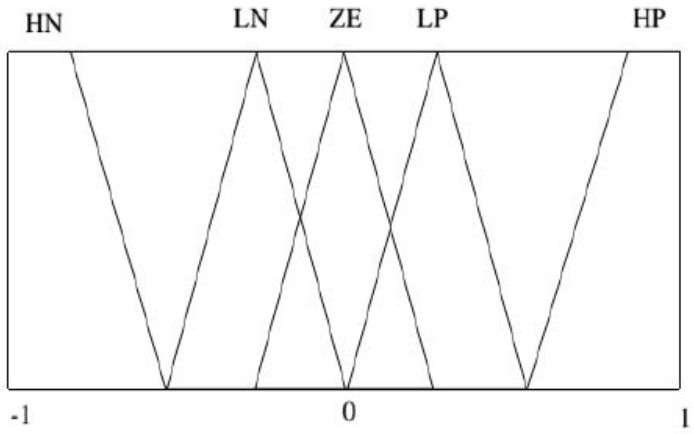

Fig. 7(B) Change In Speed Error.

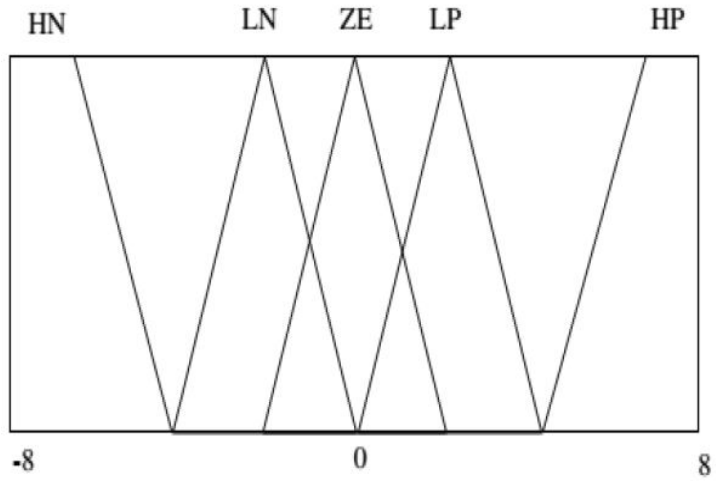

Fig. 7(C) Torque Limit. 
Table 3: Rules for FLC

\begin{tabular}{|c|c|c|c|c|c|}
\hline 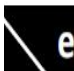 & HN & LN & ZE & $L P$ & HP \\
\hline$H P$ & ZE & $L P$ & HP & HP & HP \\
\hline$L P$ & LN & ZE & $L P$ & HP & HP \\
\hline ZE & HN & LN & ZE & LP & HP \\
\hline LN & HN & HN & LN & ZE & $L P$ \\
\hline $\mathrm{HN}$ & HN & HN & $\mathrm{HN}$ & LN & ZE \\
\hline
\end{tabular}

\section{RESULTS AND DISCUSSIONS}

A Field Oriented Controlled PMSM fed from DC supply via inverter with SVPWM using PI and FLC torque controllers is designed and simulated using MATLAB version R2010a and the results are compared. The parameters of PMSM used in simulation are given below:

\begin{tabular}{|l|l|}
\hline Rated Power & $2.25 \mathrm{HP}$ \\
\hline Number of phases & 3 \\
\hline Number of poles(p) & 8 \\
\hline Base current & $5.6 \mathrm{~A}$ \\
\hline Rated voltage & $300 \mathrm{~V}$ \\
\hline Rated speed & $2000 \mathrm{rpm}$ \\
\hline Rated torque & $8 \mathrm{~N} . \mathrm{m}$ \\
\hline Stator resistance per phase & $0.9585 \mathrm{ohm}$ \\
\hline q-axis inductance & $0.00525 \mathrm{H}$ \\
\hline d-axis inductance & $0.00525 \mathrm{H}$ \\
\hline $\begin{array}{l}\text { Stator flux linkages per } \\
\text { phase due to rotor magnet }\end{array}$ & $0.1827 \mathrm{~V} /(\mathrm{rad} / \mathrm{s})$ \\
\hline Moment of inertia & $0.0006329 \mathrm{~kg} \cdot \mathrm{m} 2$ \\
\hline Friction Factor & $0.0003035 \mathrm{~N} . \mathrm{m} /(\mathrm{rad} / \mathrm{s})$ \\
\hline
\end{tabular}

The torque ripple can be calculated by using the relation:

Torque ripple $(\%)=($ Peak to peak Torque/ Average $)$.
A. PI CONTROLLER WITH SPACE VECTOR PULSE WIDTH MODULATION

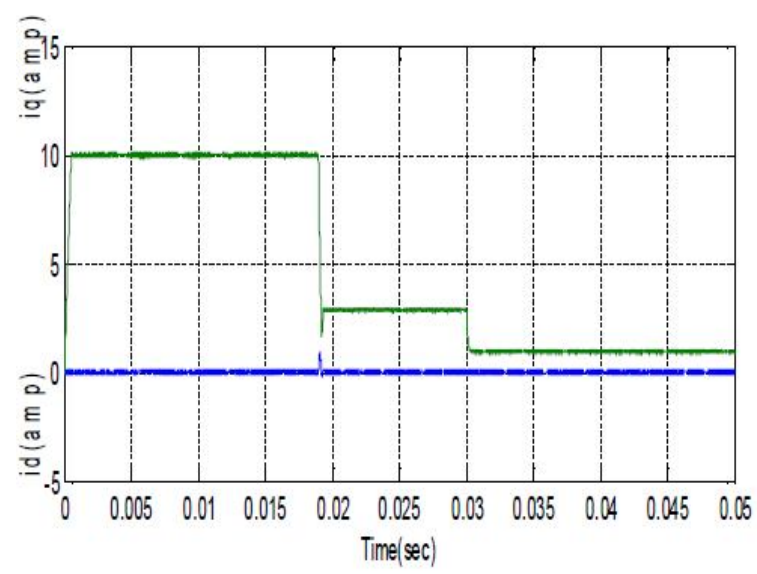

Fig. 8(A): $i_{d}$ And $i_{q}$ Currents Vs. Time

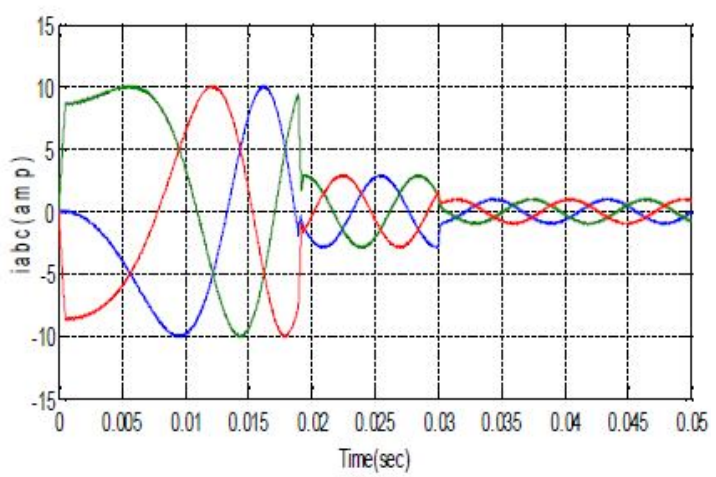

Fig. 8(B): $i_{a}, i_{b}$ And $i_{c}$ Currents Vs.Time

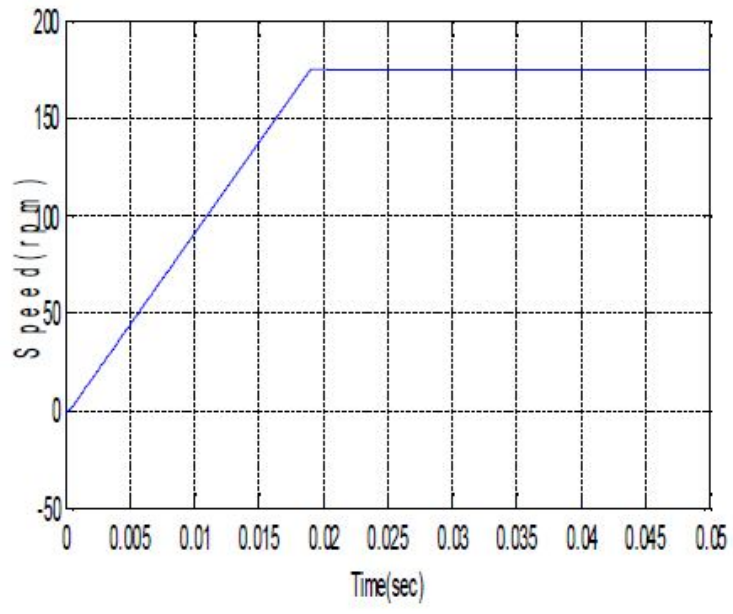

Fig. 8(C): Speed Vs. Time

The simulink model of the PMSM FOC drive is developed and the simulaton is carried out for 0.05 sec.Fig. 9(a) shows the $i_{d}$ and $i_{q}$ currents where $i_{d}$ is set to zero and $i_{q}$ is the required torque component. Fig. 8(b) shows the three phase stator currents.Fig. 8(c) shows the rotor speed in rpm and Fig. 8(d) shows the developed torque and the torque ripples. 


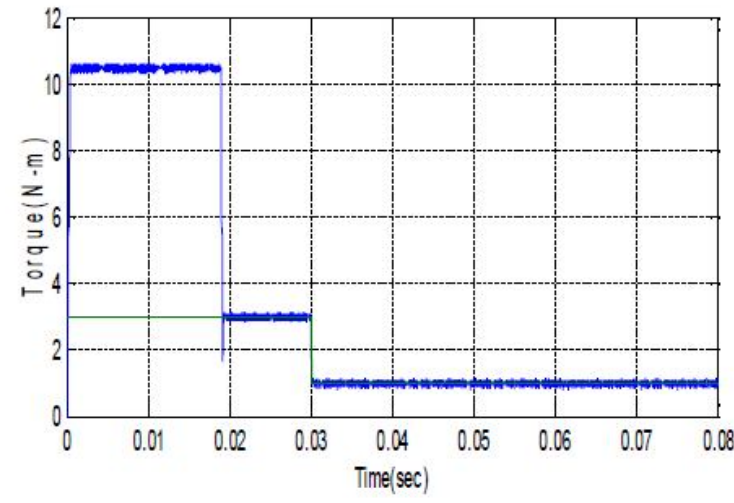

Fig. 8(D): Torque Vs. Time

Inference:

Rated Torque $=8 \mathrm{Nm}$

Torque ripple $(\%)=($ Peak to peak Torque/ Average Torque) $* 100$

$=(8.042-7.908) / 8 * 100$

$=1.675 \%$

\section{B. FUZZY CONTROLLER WITH SPACE VECTOR PULSE WIDTH MODULATION}

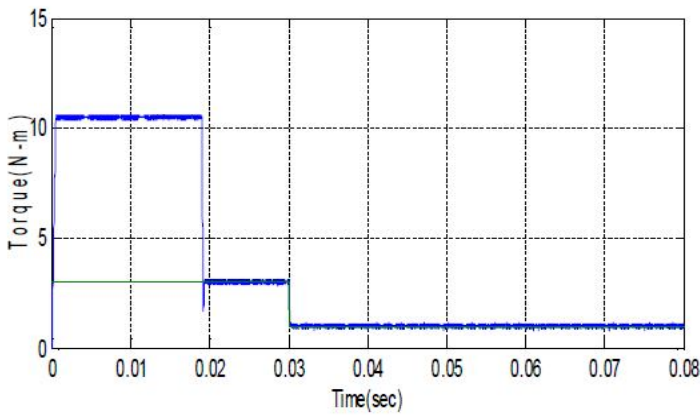

Fig. 9: Torque Vs. Time Using FLC

Fig. 9 shows the developed torque using FLC where the torque ripples are reduced as compared to that obtained using PI controller.

Inference:

Rated Torque $=8 \mathrm{Nm}$

Torque ripple $(\%)=($ Peak to peak Torque/ Average

Torque)* 100

$=(8.03-7.9071) / 8 * 100$

$=1.536 \%$

\section{DISCUSSIONS}

It is clear that the variation in Torque is less in case of Fuzzy logic controllers and they can achieve a minimum torque ripple than other control techniques. Thus by using FLC based controller, ripples are reduced to a greater extent.

\section{CONCLUSION}

Fuzzy logic controller based Torque controller model of PMSM motor drive have been analyzed and simulated using MATLAB 2010b and the results have been presented to visualize the comparison between two control techniques. The results obtained from PI torque controller demonstrate fast and satisfactory response with load perturbation. In future implementation, Hybrid PI-Fuzzy controllers can be used in replacement to PI controller

\section{REFERENCES}

[1] T.M. Jahns, " Motion control with permanent magnet ac machines, " Proc. IEEE, vol. 82, no. 8, pp. 1241-1252, Aug. 1994.

[2] F.Blaschke, "The principle of field orientation as applied to the new TRANSVEKTOR closed-loop control system for rotating field machines, "Siemens Review, vol. 39, no. 5, pp. 217-220, May 1972.

[3] K.H Bayer, H.Waldmann, and M. Weibelzahl, " Field oriented closed loop control of a synchronous machine with the NEW Transvektor control system,"Siemens Review, vol. 39, no. 5, pp.220-223, 1972.

[4] D.W. Novotny and T.A. Lipo, " Principles of vector control and field orientation, "IEEE-IAS, Introduction to Field Orientation and High Performance Drives, Tutorial Course, pp.2.1-2.65, Oct. 1985.

[5] A. V. Sant and K. R. Rajagopal, "PM synchronous motor speed control using hybrid fuzzy PI with novel switching functions," IEEE Trans. Mag., vol. 45, no. 10, pp. 4672-4675, Oct. 2009.

[6] Q. Lili, Y. Zhaohua, Q. Vi, and Z. Bo, "Analysis and design of a decoupling control strategy for three-phase voltage-source PWM converter," Tras. Of China Electrotechnical Society vol. 22, pp. 52-57, Jul. 2007. M. N. Uddin and M. A. Rahman;" High Speed Control of IPMSM Drives Using Improved Fuzzy Logic Algorithms, " IEEE Trans. Ind. Electron., vol. 54, no. 1,

[7] Liye Song and Jishen Peng, " The study of fuzzy Pi controller of Permanent Magnet Synchronous Motor," Power Electronics and Motion Control Conference, IPEMC '09. IEEE 6th International, pp. 1863-1866.

[8] Amit Vilas Sant.; K. R. Rajagopal and Nimit K. Sheth, "Permanent Magnet Synchronous Motor Drive Using Hybrid PI Speed Controller With Inherent and non inherent switching," IEEE TRANSACTIONS ON MAGNETICS, VOL. 47, NO: 10, OCTOBER 2011, Page(s): 4672 - 4675.

[9] M. Zerikat and S. Chekroun; "Design and implementation of a hybrid fuzzy controller for a high performance induction motor,

" in Proc. World Academy of Science, Engineering and Technology, Apr. 2007, vol. 20, pp. 263-269.

[10] M. Nasir Uddin.; Ronald S. Rebeiro.; " Fuzzy Logic Based Speed Controller and Adaptive Hysteresis Current Controller Based IPMSM Drive for Improved Dynamic Performance, " Electric Machines \& Drives Conference (IEMDC), 2011 IEEE International, Page(s): $1-6$.

[11] B.Adhavan, A. Kuppuswamy, G.Jayabaskaran and Dr.V.Jagannathan, " Field oriented control of Permanent Magnet Synchronous Motor (PMSM) using Fuzzy Logic Controller," Recent Advances in Intelligent Computational Systems (RAICS), 2011 IEEE, Page(s): 587 - 592.

[12] Bose B.K., Modern Power Electronics and AC Drives: Prentice Hall, 2002.

[13] Krishnan R., Electric Motor Drives: Modeling, Analysis \& Control, Prentice Hall. 2006. 